Check for updates

Cite this: RSC Adv., 2017, 7, 41376

\title{
Liquid crystal alignment behaviors on capsaicin substituted polystyrene films
}

\author{
Changha Ju, Taehyung Kim and Hyo Kang (D) *
}

\begin{abstract}
We synthesized a series of plant-based capsaincin substituted polystyrene (PCAP\#, \# =20,40,60,80, and 100 ), where \# is the molar content of the $N$-vanillylnonanamide moiety as one of the capsaicin derivatives, using polymer analogous reactions to investigate their liquid crystal (LC) alignment properties. In general, the LC cell fabricated using the polymer film having a higher molar content of $\mathrm{N}$-vanillylnonanamide side groups showed vertical LC alignment behavior. The vertical alignment behavior was well correlated with the surface energy of these polymer films. For example, vertical alignment was observed when the surface energy values of the polymer were smaller than about $29.26 \mathrm{~mJ} \mathrm{~m}^{-2}$ generated by the nonpolar, long carbon groups. Good electro-optical characteristics, such as voltage holding ratio (VHR) and residual DC voltage (R-DC), and aligning stabilities at $200{ }^{\circ} \mathrm{C}$ were observed for the $L C$ cells fabricated using PCAP100 as an eco-friendly LC alignment layer based on renewable capsaicin resource containing polymer films.
\end{abstract}

Received 27th July 2017

Accepted 18th August 2017

DOI: $10.1039 / c 7 r a 08321 a$

rsc.li/rsc-advances

mechanical rubbing is one of the conventional methods used to

\section{Introduction}

Liquid crystals (LCs) have attracted considerable interest due to their fluidity and crystal-like order. ${ }^{1}$ Generally, LC molecules have been known to have anisotropic physicochemical properties induced by external stimuli such as electric and magnetic fields due to their unique chemical structure, ${ }^{2}$ which has been widely applied in diverse fields. For example, extensive studies have focused on the fabrication of electro-optical components including acoustic polarizers, ${ }^{3}$ tunable lasers, ${ }^{4}$ color filters, ${ }^{5}$ and compensation films $\mathrm{s}^{6}$ using LC molecules. Additionally, there have been several studies concerning optical switching devices such as smart windows, ${ }^{7}$ and digital glasses ${ }^{8}$ using polymer dispersed liquid crystal (PDLC) technology. As another example, LCs can be utilized as responsive sensors for external stimuli such as temperature, ${ }^{9}$ gas, ${ }^{10}$ flow, ${ }^{11}$ and humidity ${ }^{12}$ based on color changes. Interestingly, LCs have been recognized as materials for biomedical applications such as in biomedicine ${ }^{13}$ and biosensors to detect biomolecules such as viruses, bacteria, and proteins on surfaces. ${ }^{14}$ In particular, LC has been applied extensively, driven by increasing needs in display application, transmissive type using nematic LC and reflective type using cholesteric LC, respectively, such as TVs, monitors, smart phones, notebooks, and tablet PCs. ${ }^{15}$ It is essential to align the LC molecules having optical anisotropy and dielectric anisotropy on the substrate in one direction,${ }^{16}$ which play a vital role in the LC alignment technique for display. Generally,

Department of Chemical Engineering, Dong-A University, 37 Nakdong-Daero 50beon-gil, Saha-gu, Busan 604-714, Korea. E-mail: hkang@dau.ac.kr; Fax: +82 51 200 7728; Tel: +82512007720 produce a uniform orientation of LC molecules. ${ }^{17}$ The mechanical rubbing of polymeric surfaces is the most widely used technique to make the uniform alignment of the LC molecules in the manufacture of liquid crystal display (LCD) ${ }^{18-23}$ Through rubbing process, polyimide derivatives are mostly normally employed as LC alignment layers because they provide very stable LC alignment. ${ }^{24-33}$ Polyimide derivatives having long alkyl or alkyloxy groups, such as semi-flexible copolyimides containing $n$-octadecyl side groups and polyimides with (n-decyloxy)biphenyloxy side groups, show vertical LC alignment behaviors. ${ }^{34-37}$ The vertical LC alignment layer on the polystyrene (PS) derivatives having long alkyl or fluoroalkyl groups can be formed. For example, LC cells fabricated using a nematic LC and rubbed polymer films of $n$-alkylsulfonylmethyl- or $n$-alkylthiomethyl-substituted polystyrenes having more than 8 carbons (number of alkylcarbon $>8$ ) show vertical LC alignment behaviors. ${ }^{38}$ The LC cells fabricated from $n$ alkylsulfonylmethyl- or $n$-alkylthiomethyl-substituted polystyrenes having longer alkyl group very stable vertical LC alignment with a pretilt angle of about $90^{\circ}$, because their long alkyl group can produce low surface energy due to the steric effect by effective packing structures of alkyl groups on the top surface of polymer films. ${ }^{38}$ The LC cells made from the 4alkylphenoxymethyl-substituted polystyrenes showed vertical LC alignment behaviors even at a very high rubbing density of 250 , regardless of the length of the alkyl side groups. ${ }^{39}$ The unique side chain structure, consisting of two phenyl groups and an alkyl group in the 4 position of the phenoxy groups of 4alkylphenoxymethyl-substituted polystyrenes, imparts strong vertical LC alignment behavior having high pretilt angles, 
regardless of rubbing density. ${ }^{39}$ Not only the surface energy values of the polymers, but also the molecular orientation such as isomeric functional side groups on the polymer surfaces, are important factors in obtaining vertical LC alignment behavior due to the different steric repulsions or interactions between the LC molecules and the surfaces.

Capsaicin is one of the eco-friendly and non-toxic substances classified as capsaicinoids, ${ }^{\mathbf{4 0}}$ which has a spicy taste when eaten, and is a natural extract derived from chili, pepper, and paprika. Capsaicin is the standard substance of the Scoville scale which is an international standard index of spicy taste. Capsaicin has been known to have non-toxicity against human body, which can be supplied in an analgesic for topical parts associated with muscles, joints and used as ointment for pruritus to relief pains. $^{\mathbf{4 1 , 4 2}}$ Capsaicin has a chemical structure of phenolic aromatic compound with antimicrobial activity. ${ }^{43-45}$ Capsaicin has been known to contribute to the inhibition of the growth of pathogenic bacteria. ${ }^{46}$ For example, capsaicin has been confirmed to improve the antibacterial effects of Bacillus subtilis, Bacillus cereus, and Sarcina lutea as well. ${ }^{47}$ Vanillin, one of the capsaicin derivatives, has been shown inhibitory activity towards the growth of yeast and mold..$^{48,49}$ Capsaicin can be used to modify the surfaces on substrates such as metal and glass using hydroxy group via primary and secondary bonding for a variety of film applications. Chemical composition of alkyl group in the capsaicin attached to the surfaces can control the wetting characteristics on the top surface of the various substrates by changing the content of the capsaicin. ${ }^{50,51}$

In this study, plant-based capsaicin-substituted polystyrenes (PCAP\#) were synthesized to obtain the vertical alignment of the LCs and to study the effect of the molar contents of the side groups on the LC alignment behavior. The optical and electrical properties of the LC cells fabricated using the polymer films are also included.

\section{Experimental}

\section{Materials}

4-Chloromethylstyrene, $\mathrm{N}$-vanillylnonanamide, and potassium carbonate were purchased from Aldrich Chemical Co. and a nematic LC, MLC-6608 $\left(n_{\mathrm{e}}=1.5586, n_{\mathrm{o}}=1.4756\right.$, and $\Delta \varepsilon=$ -4.2 , where $n_{\mathrm{e}}, n_{\mathrm{o}}$, and $\Delta \varepsilon$ represent extraordinary refractive indexes, ordinary refractive indexes, and dielectric anisotropy, respectively), was purchased from Merck Co. $N, N^{\prime}$-Dimethylacetamide (DMAc) and ethanol were dried over molecular sieves (4 $\AA$ ). Tetrahydrofuran (THF) was dried by refluxing with benzophenone and sodium followed by distillation. 4-Chloromethylstyrene was purified by column chromatography on silica gel using hexane as an eluent to remove any impurities and inhibitors (tert-butylcatechol and nitroparaffin). Poly(4chloromethylstyrene) (PCMS of $M_{\mathrm{n}}=22000$ and $M_{\mathrm{w}} / M_{\mathrm{n}}=$ 2.02) was synthesized through conventional free radical polymerization of the 4-chloromethylstyrene using 2,2'-azoisobutyronitrile (AIBN) under a nitrogen atmosphere. The solution mixture was cooled to room temperature and then poured into methanol to obtain a white precipitate. The precipitate was further purified by soxhlet extraction using hot methanol to remove remaining monomer (4-chloromethylstyrene) and low molecular weight PCMS. AIBN (Junsei Chemical Co., Ltd.) was used as an initiator. The AIBN was purified from crystallization using methanol. All other reagents and solvents were used as received.

\section{Preparations of capsaicin modified polystyrene}

The following procedure was used to synthesize all of the capsaicin-substituted polystyrenes, PCAP\#, where \# represent the molar content (\%) of $N$-vanillylnonanamide moiety in the side group. The synthesis of the capsaicin-substituted polystyrene (PCAP100) is given as an example. A mixture of $\mathrm{N}$ vanillylnonanamide (2.89 g, $9.83 \mathrm{mmol}, 150 \mathrm{~mol} \%$ compared with PCMS) and potassium carbonate $(1.631 \mathrm{~g}, 11.81 \mathrm{mmol})$ in $N, N^{\prime}$-dimethylacetamide (DMAc, $30 \mathrm{~mL}$ ) was heated to $75^{\circ} \mathrm{C}$. A PCMS ( $1 \mathrm{~g}, 6.56 \mathrm{mmol})$ solution in DMAc $(20 \mathrm{~mL})$ was added to the mixture and then magnetically stirred at $70{ }^{\circ} \mathrm{C}$ for $24 \mathrm{~h}$ under a nitrogen atmosphere. The solution mixture was cooled to room temperature and then poured into methanol to obtain a white precipitate. The precipitate was further purified by several reprecipitations from DMAc solution into methanol and then washed with hot methanol to remove potassium carbonate and any remaining salts. The PCAP100 was obtained in yields above $80 \%$ after drying overnight in a vacuum. The degree of substitution of the chloromethyl to the capsaicin group was found to be almost $100 \%$ within experimental error. The product was obtained in above $80 \%$ yield after drying overnight in a vacuum.

PCAP100 ${ }^{1} \mathrm{H}$ NMR $\left(\mathrm{CDCl}_{3}\right): \delta=0.8-1.9(18 \mathrm{H}), 2.1-2.3(2 \mathrm{H})$, 3.5-3.9 (3H), 4.1-4.3 (2H), 4.7-5.0 (2H), 6.3-7.2 (4H).

Other polystyrene derivatives containing capsaicin side groups were synthesized from the same procedure used for the preparation of PCAP100 except for differing amounts of $\mathrm{N}$ vanillylnonanamide in the reaction. For example, PCAP80, PCAP60, PCAP40, and PCAP20 were prepared with $N$-vanillylnonanamide of $1.53 \mathrm{~g}$ (5.21 mmol), $1.15 \mathrm{~g}$ (3.92 mmol), $0.76 \mathrm{~g}$ (2.59 mmol), and $0.38 \mathrm{~g}(1.30 \mathrm{mmol})$, respectively, using slight excess amounts of potassium carbonate $(1.631 \mathrm{~g}, 11.81 \mathrm{mmol}$, 180 mol\% compared with PCMS).

\section{Film preparation and LC cell assembly}

Solutions of PCAP\# in tetrahydrofuran (1 wt $\%$ ) were prepared, respectively. These solutions were filtered using a PTFE membrane with a pore size of $0.45 \mu \mathrm{m}$. Thin films of the polymers were prepared by spin-coating ( $2000 \mathrm{rpm}, 60 \mathrm{~s}$ ) onto glass substrates. LC cells were fabricated using the polymer film onto glass slides. The LC cells were constructed by assembling the films together using spacers with thicknesses of $4.25 \mu \mathrm{m}$. The cells were filled with nematic LC, MLC-6608. The manufactured LC cells were sealed with epoxy glue.

\section{Instrumentation}

The ${ }^{1} \mathrm{H}$ NMR measurements were carried out on a Bruker AVANCE spectrometer at $300 \mathrm{MHz}$. The gel permeation chromatography (GPC) was used to measure the number average molecular weight $\left(M_{\mathrm{n}}\right)$ and polydispersity index $\left(M_{\mathrm{w}} / M_{\mathrm{n}}\right)$ of the 
synthesized polymer with respect to polystyrene standards using tetrahydrofuran (THF) as the eluent and an UV detector. The optical transmittance of the polymer films onto glass substrates was obtained using UV-Vis spectroscopy (Perkin Elmer Lamda 20 spectrometer). Surface roughness, $R_{\text {rms }}$, was obtained by atomic force microscopy (AFM) and $R_{\text {rms }}$ values of the polymers were less than $1 \mathrm{~nm}$. Since the $R_{\mathrm{rms}}$ values of these polymers are very small, the influences of surface roughness on the contact angles can be ignored in all contact angle measurements. The contact angles of distilled water and methylene iodide on the polymer films were determined with a Kruss DSA10 contact angle analyzer equipped with drop shape analysis software. The surface energy value was calculated using the Owens-Wendt's equation as

$$
\gamma_{\mathrm{sl}}=\gamma_{\mathrm{s}}+\gamma_{1}-2\left(\gamma_{\mathrm{s}}^{\mathrm{d}} \gamma_{1}^{\mathrm{d}}\right)^{1 / 2}-2\left(\gamma_{\mathrm{s}}^{\mathrm{p}} \gamma^{\mathrm{p}}\right)^{1 / 2}
$$

where $\gamma_{1}$ is the surface energy of the liquid, $\gamma_{\mathrm{sl}}$ is the interfacial energy of the solid/liquid interface, $\gamma_{\mathrm{s}}$ is the surface energy of the solid, $\gamma_{1}{ }^{\mathrm{d}}$ and $\gamma_{\mathrm{l}}^{\mathrm{p}}$ are known for the test liquids, $\gamma_{\mathrm{s}}{ }^{\mathrm{d}}$ and $\gamma_{\mathrm{s}}^{\mathrm{p}}$ can be calculated from the measured static contact angles. ${ }^{52}$ The polarized optical microscopy (POM) images of the LC cell were taken using an optical microscopy (Nikon, ECLIPSE E600 POL) equipped with a polarizer and digital camera (Nikon, COOLPIX995). The pretilt angle of antiparallel LC cell was measured by rotating the LC cell by the crystal rotation method. ${ }^{53}$ The voltage holding ratio (VHR) was measured using a VHR measurement system (autronic-MELCHERS, VHRM 105). The pulse width, frame frequency, and data voltages were $64 \mu \mathrm{s}$, $60 \mathrm{~Hz}$, and $1.0 \mathrm{~V}$, respectively. The measurement temperatures were 25 and $60{ }^{\circ} \mathrm{C}$. The residual DC voltage (R-DC) value was evaluated using a capacitance-voltage $(C-V)$ hysteresis method, which is used by Nissan Chemical Industries, Ltd.

\section{Results and discussion}

Fig. 1 shows the synthetic routes to the capsaicin-substituted polystyrenes (PCAP100) and copolymers (PCAP80, PCAP60, PCAP40, and PCAP20, where \# is the molar content (\%) of $\mathrm{N}$ -

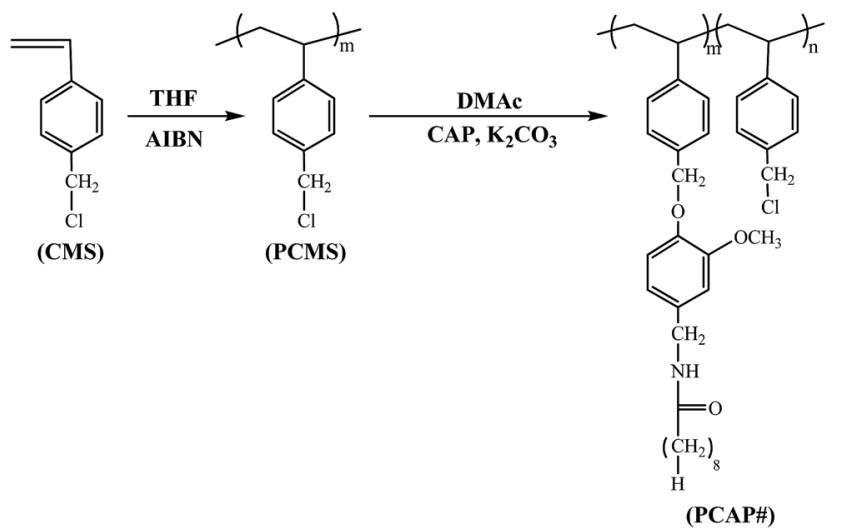

Fig. 1 Synthetic route to capsaincin-substituted polystyrene films (PCAP\#), where \# indicate the mole percent of $N$-vanillylnonanamide containing monomeric units in the polymer. vanillylnonanamide side groups). The copolymers with different degrees (\%) of substitution were obtained by varying the amounts of $N$-vanillylnonanamide in the reaction. Almost $100 \%$ conversions from chloromethyl to capsaicin were obtained, when 150 mol\% of $N$-vanillylnonanamide was used at $75{ }^{\circ} \mathrm{C}$ for $24 \mathrm{~h}$, as shown in ${ }^{1} \mathrm{H}$ NMR spectra and assignment of the respective proton peaks of capsaicin-containing homopolymer (PCAP100) (Fig. 2).

The chemical compositions of monomeric units in the obtained polymers were confirmed by ${ }^{1} \mathrm{H}$ NMR spectra. The ${ }^{1} \mathrm{H}$ NMR spectrum and assignment of the respective peaks of the PCAP100 were shown in Fig. 2. ${ }^{1} \mathrm{H}$ NMR spectrum of PCAP100 indicates the presence of protons from the phenyl ring of styrene backbone $(\delta=6.3-7.2 \mathrm{ppm}$ (peak a)). The proton peaks from capsaicin side chains $(\delta=4.1-4.3$ (peak c), 4.7-5.0 (peak d), 2.1-2.3 (peak e) indicate the inclusion of capsaicin moieties in the polymer. The content of CAP could be calculated by comparing the integration value of proton peaks of the CAP $(\delta=$ 4.1-4.3 and 4.7-5.0 ppm, peak c and d) and chloromethyl side chains $(\delta=4.7-5.0 \mathrm{ppm}$, peak b). Similar integrations and calculations for PCAP80, PCAP60, PCAP40, and PCAP20 were performed and were typically within $\pm 5 \%$ of the expected values from the synthesis.

The average molecular weights $\left(M_{\mathrm{n}}\right)$ of these polymer series synthesized from the PCMS $\left(M_{\mathrm{n}}=22000\right)$ were always larger than 24000 indicating that polymer modification from PCMS to the polymers in this paper gave rise to increase of average molecular weights of polymers, as expected (Table 1). These polymers are soluble in many medium-polarity solvents having low boiling points, such as tetrahydrofuran and chloroform, and in aprotic polar solvents, such as $N, N^{\prime}$-dimethylformamide, $N, N^{\prime}$-dimethylacetamide, and $N$-methyl-2-pyrrolidone. The solubility of all samples for various solvents is good enough to be used as thin film materials for flexible devices. Among the organic solvents, tetrahydrofuran was chosen as a coating solvent for thin film fabrication, as it has low eco-toxicity and good bio-degradability. ${ }^{54}$ The thermal properties of these polymers were examined using differential scanning calorimetry (DSC). All the polymers were amorphous because there was only one glass transition observed from their DSC thermogram (Fig. 3).

As the molar content of the $N$-vanillylnonanamide side group increased, the $T_{\mathrm{g}}$ value decreased from $108^{\circ} \mathrm{C}$ for PCMS to $42{ }^{\circ} \mathrm{C}$ for PCAP100 (Table 1). Generally, the $T_{\mathrm{g}}$ of polymers depends on the polarity, flexibility, and bulkiness of the side group. The $T_{\mathrm{g}} \mathrm{S}$ of the polymers was reported to increase with increasing polarity of the side group, ${ }^{55}$ while the $T_{\mathrm{g}}$ of the polymers can increase or decrease with increasing bulkiness of the side group. For example, the $T_{\mathrm{g}}$ of the poly(vinylnaphthalene) with relatively bulky substituents, such as naphthalene, is higher than that of polystyrene. ${ }^{55}$ This means that the incorporation of a bulky side group, such as $N$-vanillylnonanamide, can decrease the flexibility of the polymer backbone. In this case, the incorporation of a bulky side group increases the free volume in the polymer without increasing the intermolecular interactions much, if any, which decreases $T_{\mathrm{g}}{ }^{56-58}$ 


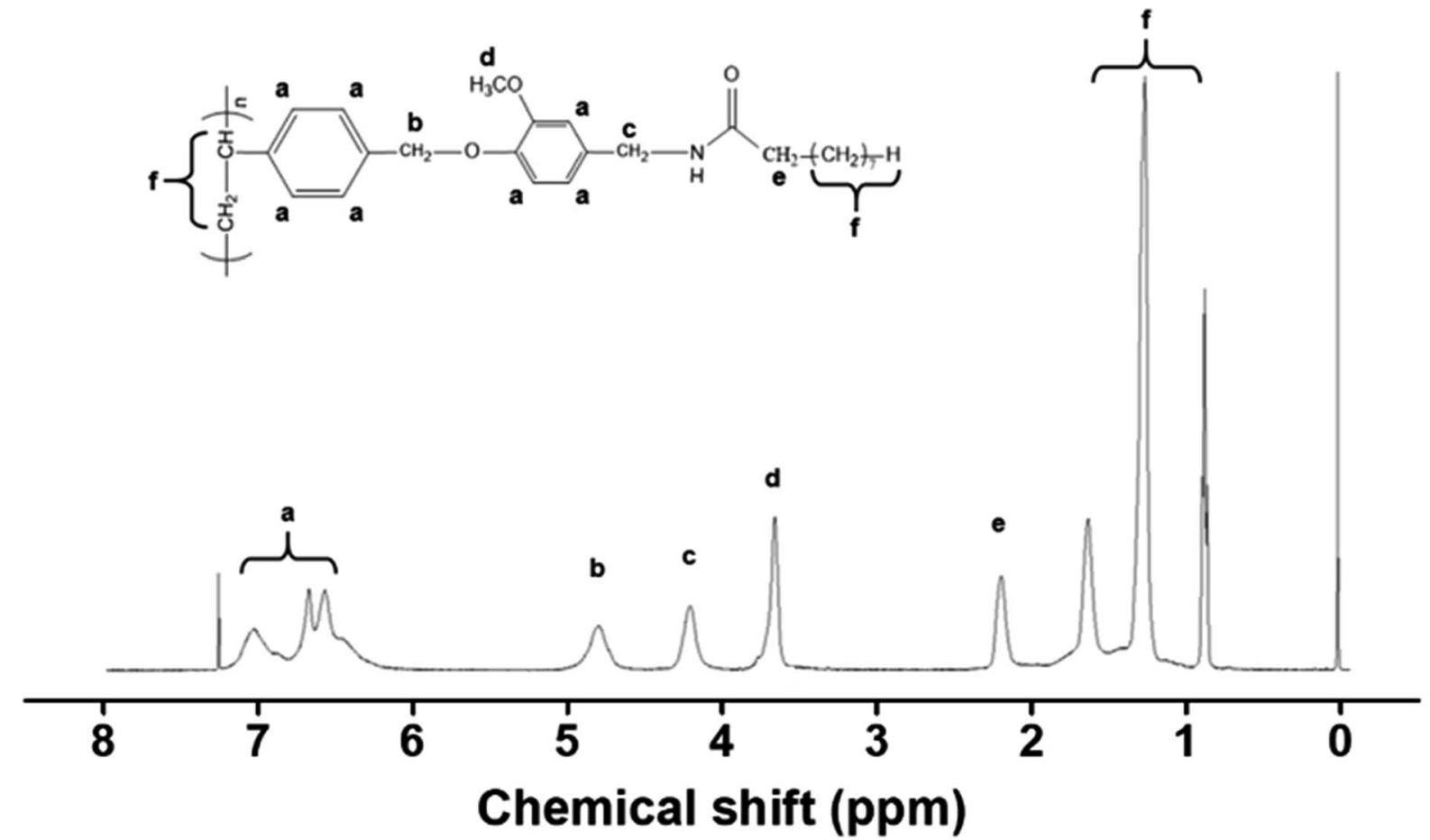

Fig. $2{ }^{1} \mathrm{H}$ NMR spectrum of PCAP100.

Table 1 Reaction conditions and results for the synthesis of the PCMS and PCAP\#

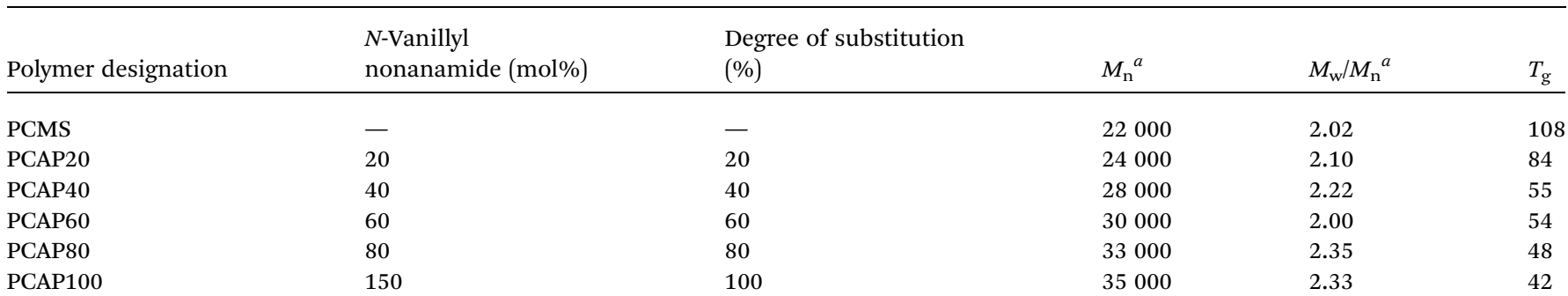

${ }^{a}$ Obtained from GPC using THF as solvent with respect to monodisperse polystyrene as standard.

Quantitative analysis of transparency of PCAP\# films was evaluated using UV-Vis spectra to investigate the possibility for the surface coating applications (Fig. 4). The transmittance value of the coated PCAP100 film onto glass substrate is in range of $93.7 \%$ at $550 \mathrm{~nm}$, which is higher than that $(80.5 \%)$ of the widely used polyimide film having intrisical yellowish coloration problem related to the diimide fragment conjugation as a LC alignment layer. Conclusively, the optical transparency of the PCAP\# film in the visible light region is good enough to be used as optical materials for display devices.

Fig. 5 shows the images of the LC cells made from these copolymers (PCAP\#). The LC cells fabricated with the PCAP\# films having $N$-vanillylnonanamide side group content of less than about $80 \mathrm{~mol} \%$ (PCMS, PCAP20, PCAP40, PCAP60, and PCAP80) partially show LC textures with birefringence, while good uniformity of the vertical LC alignment behavior was observed for the LC cells fabricated with the polymer films having $N$-vanillylnonanamide side group content of $100 \mathrm{~mol} \%$

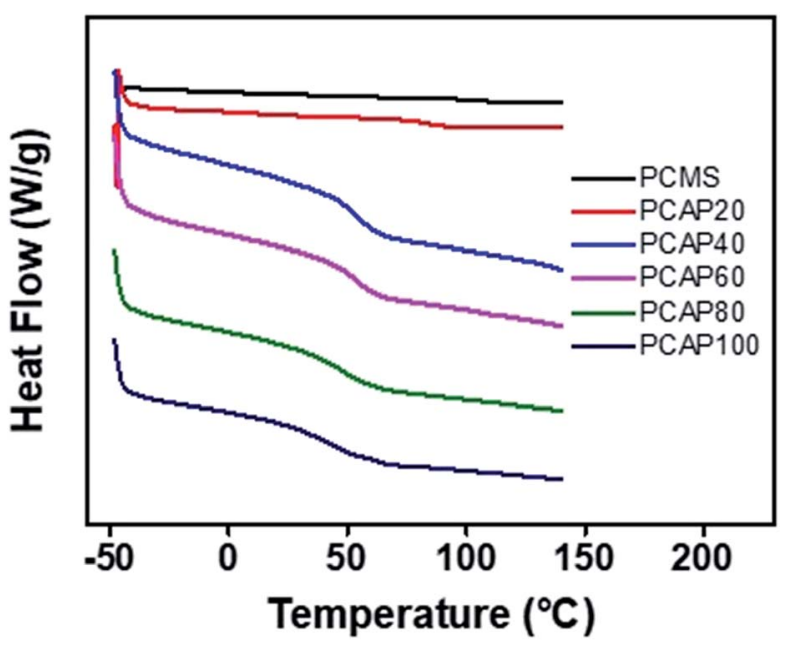

Fig. 3 DSC thermogram of PCAP\#. 


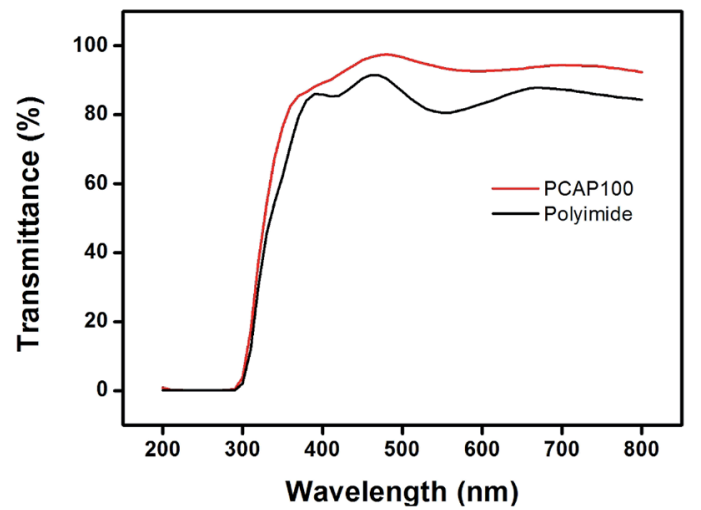

Fig. 4 UV-Vis transmittance spectra of PCAP\# and polyimide alignment layers onto quartz substrates.

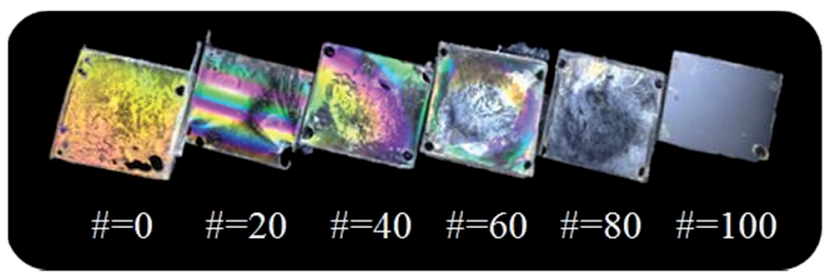

Fig. 5 Photograph images of the LC cells fabricated with PCAP\# films according to the molar content of $N$-vanillylnonanamide moiety.

(PCAP100) in the whole area in the photograph images. All of the PCAP100 films were able to produce stable vertical LC alignment layers and the vertical LC alignment was maintained for at least more than several months since we first made the LC cells from these polymers. Therefore, as the molar content of the $N$-vanillylnonanamide side groups increases, the vertical LC aligning ability of the LC cell increases.

The LC alignment behaviors of the LC cells fabricated with the PCAP\# films were investigated by observing the polarized optical microscopy (POM) images (Fig. 6). Random planar LC alignment was observed for the LC cells fabricated using the PCMS film. When the molar content of the $N$-vanillylnonanamide containing monomeric unit in the PCAP\# was less than $40 \%$, the LC cells fabricated with the PCAP\# film showed planar LC alignment in the conoscopic images. On the other hand, partial random planar and random tilted LC alignment of the LC cells fabricated using the polymer films (PCAP60 and PCAP80), were observed. The pretilt angle of the LC cell made polymer film was measured, in order to determine the LC

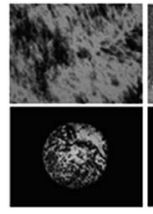

PCMS

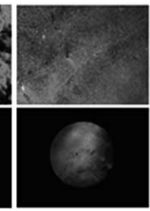

PCAP20

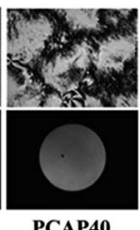

PCAP40

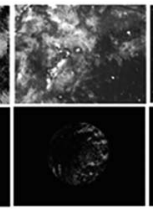

PCAP60

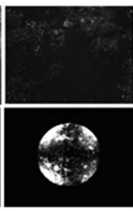

PCAP80

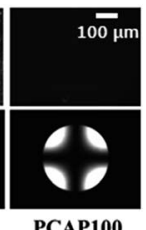

PCAP100
Fig. 6 POM images of the LC cells made from PCMS film and PCAP\# (PCAP20, PCAP40, PCAP60, PCAP80, and PCAP100) films. alignment direction. The LC cells made from PCMS, PCAP20, PCAP40, PCAP60, and PCAP80 could not be observed due to their random LC alignment behaviors. All of the PCAP100 films were able to produce stable vertical LC alignment layers having a Maltese cross pattern. The pretilt angle of the LC on the PCAP100 film is about $90^{\circ}$.

Based on the results obtained for the LC alignment behavior, we found a general trend that the polymers having higher molar contents of $N$-vanillylnonanamide side groups have a preference for vertical LC alignment. It has been known that the high pretilt angles of LC molecules to produce vertical alignment behavior are related to the low surface energy of the alignment layer surfaces and/or the steric repulsions between LC molecules and the alignment layers. ${ }^{59,60}$ For example, polyimide derivatives having the nonpolar and bulky groups such as pentylcyclohexylbenzene ${ }^{59}$ and 4-(n-octyloxy)phenyloxy ${ }^{60}$ showed the vertical alignment behavior. Therefore, we tried to explain the LC alignment behaviors on the PCAP\# films using several surface characterization techniques, viz. surface energy value measurements.

Fig. 7 and Table 2 show the surface energy values of the polymer films obtained based on the static contact angles of water and methylene iodide. The total surface energy was calculated using the Owens-Wendt's equation and this value is a summation of the polar and dispersion contributions. We also found that there are critical surface energy values of the polymers to give vertical LC alignment behavior. The vertical LC alignment was observed from the PCAP100 films. The total surface energy value of this polymers is $29.26 \mathrm{~mJ} \mathrm{~m}^{-2}$, whereas the other polymers having total surface energy values larger than about $30.95 \mathrm{~mJ} \mathrm{~m}^{-2}$ such as PCMS $\left(45.67 \mathrm{~mJ} \mathrm{~m}^{-2}\right)$, PCAP20 $\left(46.05 \mathrm{~mJ} \mathrm{~m}^{-2}\right), \operatorname{PCAP} 40\left(36.89 \mathrm{~mJ} \mathrm{~m}^{-2}\right)$, PCAP60 $\left(32.24 \mathrm{~mJ} \mathrm{~m}^{-2}\right)$, and PCAP80 $\left(30.95 \mathrm{~mJ} \mathrm{~m}^{-2}\right)$ did not show vertical alignment behavior. Therefore, it is very reasonable to say that the vertical aligning ability of PCAP100 is due to the increased steric repulsions between LC molecules and polymer surfaces by incorporating the nonpolar and bulky capsaincin moieties into the side group of polystyrene and the low surface energy $\left(<29.26 \mathrm{~mJ} \mathrm{~m}^{-2}\right)$ originating from its unique chemical structure of the nonpolar and long carbon groups.

The reliability of the LC cells made from the polymer films was investigated through a stability test of the LC alignment under harsh condition such as high temperatures. The thermal stability of the LC cell made from the PCAP100 film was estimated from the POM image after heating for $10 \mathrm{~min}$ at 100, 150, and $200^{\circ} \mathrm{C}$, respectively. As shown in Fig. 8, the distinguishable difference of pretilt angle on PCAP100 film having vertical LC aligning ability cannot be observed through Maltese cross pattern in conoscopic POM images, indicating that the vertical LC aligning ability of the PCAP100 LC cell was found to be maintained even at the high temperature.

The total surface energy values of the PCAP100 films obtained based on the static contact angles of water and methylene iodide were also measured after heating. When the temperature increased to $200{ }^{\circ} \mathrm{C}$, total surface energy value, one of the film properties, of the PCAP100 film was maintained in the range of about $29.00-30.00 \mathrm{~mJ} \mathrm{~m}^{-2}$. The electro-optical (E-O) 

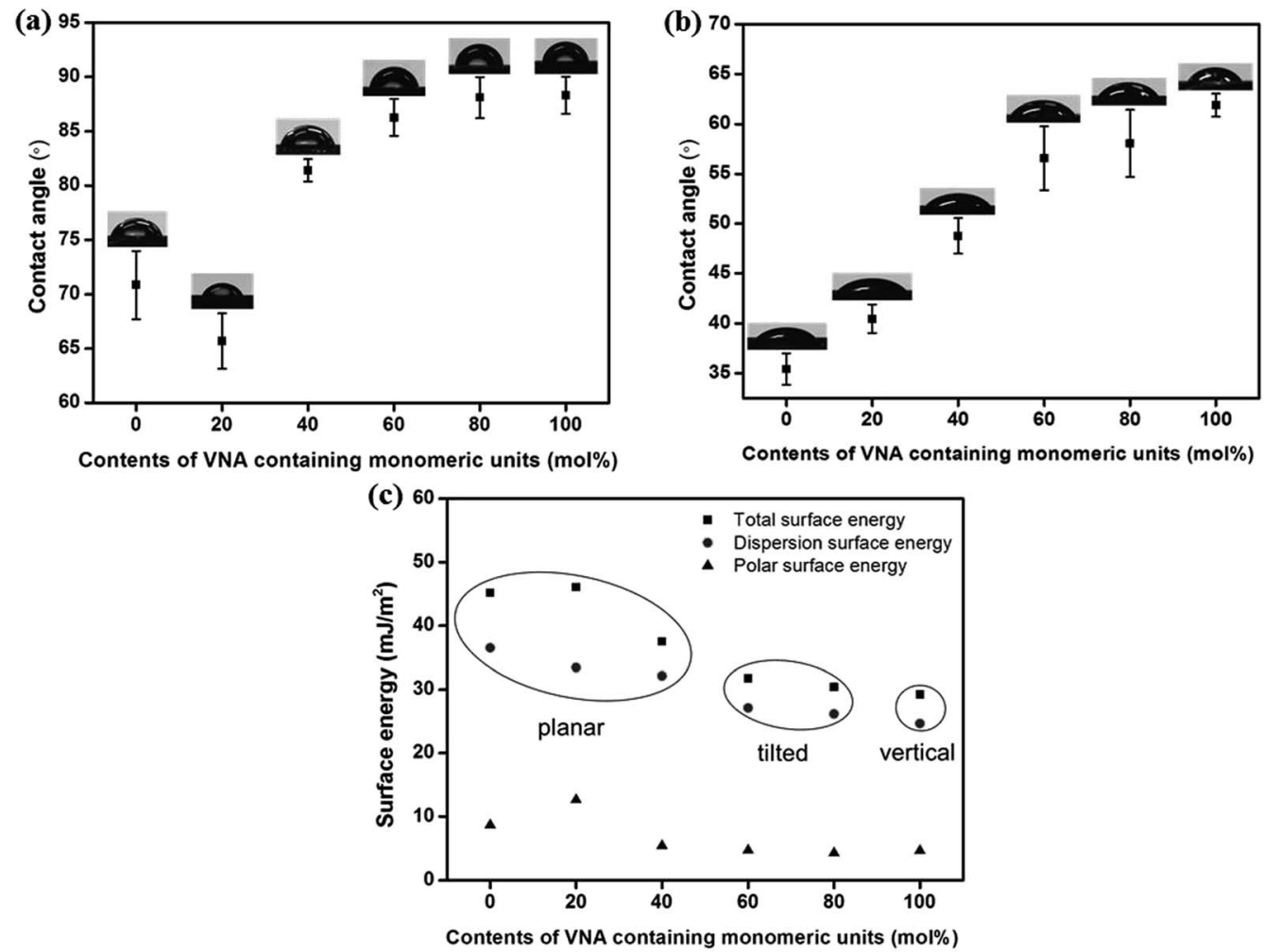

Fig. 7 (a) Water, (b) diiodomethane contact angle, and (c) surface energy values of PCAP\# films according to the molar content of the $N$ vanillylnonanamide moiety in the side groups.

Table 2 Surface energy values and LC alignment properties

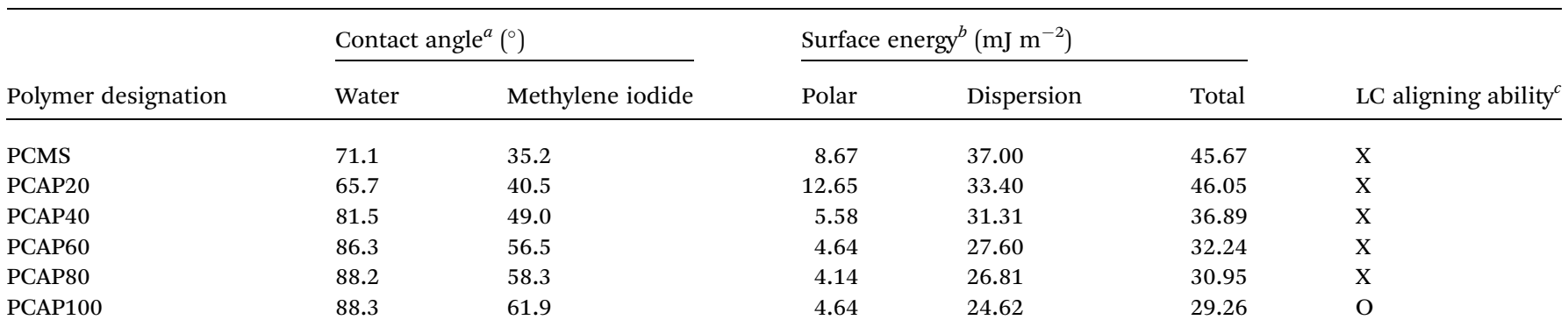

${ }^{a}$ Measured from static contact angles. ${ }^{b}$ Calculated from Owens-Wendt's equation. ${ }^{c}$ Circle $(\mathrm{O})$ and cross $(\mathrm{X})$ indicate polymer film have vertical and random planar, tilted LC aligning ability, respectively.

performance of the LC cell fabricated with the PCAP100 film was measured for the possible practical LC display application. The LC cell exhibited a voltage holding ratio (VHR) of above

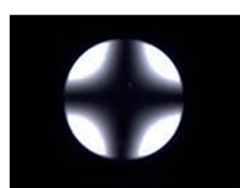

$100{ }^{\circ} \mathrm{C}$

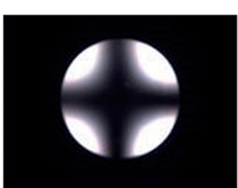

$150{ }^{\circ} \mathrm{C}$

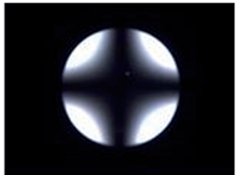

$200{ }^{\circ} \mathrm{C}$
Fig. 8 Concoscopic POM images of the LC cells made PCAP\# films, after thermal treatment at 100,150 , and $200{ }^{\circ} \mathrm{C}$ for $10 \mathrm{~min}$, respectively.
$99 \%$ at $25{ }^{\circ} \mathrm{C}$ and this value was maintained at $60{ }^{\circ} \mathrm{C}$. It is sufficiently high for practical applications as the LC alignment layer in TFT addressed LCD. ${ }^{1}$ The residual DC voltage (R-DC) of the LC cell measured using the capacitance-voltage $(C-V)$ hysteresis method was found to be very low, less than $10 \mathrm{mV}$, which is even smaller than that of commercial polyimides. ${ }^{1}$ The excellent thermal stability, VHR, and R-DC of the LC cell made from PCAP100 film was ascribed to the intrinsic property of the hydrocarbonated polymers such as good thermal stability and low dielectric constant.

Recently, considerable effort has been made to develop plastic substrates for flexible LC displays. ${ }^{61}$ All of the LC cells made from the unrubbed PCAP\# films on PET (polyethylene terephthalate) substrates exhibit similar LC alignment behavior 
compared with the LC cells made from same polymer films on glass substrates as previously shown in Fig. 6. We found that the LC cells fabricated using the PCAP100 film on plastic PET substrates show vertical LC alignment behavior. Furthermore, this LC cell showed very nice vertical LC aligning ability which was maintained after bending it several hundred times. Therefore, PCAP100 having plant-based and renewable resources can be considered as candidate LC alignment layers for eco-friendly flexible LC displays, such as in VA (vertical alignment) mode applications.

\section{Conclusions}

A series of polystyrene derivatives containing plant-based and renewable $\mathrm{N}$-vanillylnonanamide (VNA), one of the capsaicin derivatives, (PCAP\#), were synthesized to investigate liquid crystal (LC) alignment property of these polymer films. The LC cells made from the films of the polymers having $100 \mathrm{~mol} \%$ of VNA units (PCAP100) showed vertical LC alignment in the whole area. However, when the molar content of the VNA containing monomeric unit in the PCAP\# was less than 80\% (PCMS, PCAP20, PCAP40, PCAP60, and PCAP80), the LC cells fabricated with the PCAP\# films did not show nice vertical LC alignment. PCAP100 polymer films exhibited good optical transparency in the visible light region (400-700 $\mathrm{nm})$. For example, transmittance value $(93.7 \%)$ of the PCAP100 film onto glass substrate at $550 \mathrm{~nm}$ is better that $(80.5 \%)$ of the polyimide film, the most commonly used LC alignment layers. The vertical LC alignment was ascribed to the steric repulsions between the LC molecule and the polymer surface due to the incorporation of a nonpolar and bulky capsaicin moiety into the side chain and was well correlated with the surface energy values of the polymer having smaller than about $29.26 \mathrm{~mJ} \mathrm{~m}^{-2}$, generated by the long alkyl groups. This can give the basic idea for the design of LC alignment layers based on renewable capsaicin resource containing polymer films.

\section{Conflicts of interest}

"There are no conflicts to declare".

\section{Acknowledgements}

This research was supported by the Basic Science Research Program through the National Research Foundation of Korea (NRF) funded by the Ministry of Education, Science and Technology (NRF-2015R1C1A1A01051654). Financial supports by the Dong-A University Research Fund are gratefully acknowledged.

\section{Notes and references}

1 P.-G. d. Gennes and J. Prost, in The Physics of Liquid Crystals, Oxford University Press, 2nd edn, 1995, pp. 1-2.

2 R. B. Meyer, Appl. Phys. Lett., 1968, 12, 281-282.

3 D. Lacey, H. Beattie, G. Mitchell and J. Pople, J. Mater. Chem., 1998, 8, 53-60.
4 H. Hirschmann, P. Roberts, F. Davis, W. Guo, C. Hasson and G. Mitchell, Polymer, 2001, 42, 7063-7071.

5 Y. Huang and S. Zhang, Opt. Lett., 2011, 36, 4563-4565.

6 H. Mori, Y. Itoh, Y. Nishiura, T. Nakamura and Y. Shinagawa, Jpn. J. Appl. Phys., 1997, 36, 143-147.

7 R. Baetens, B. P. Jelle and A. Gustavsen, Sol. Energy Mater. Sol. Cells, 2010, 94, 87-105.

8 C. Lampert, Sol. Energy Mater. Sol. Cells, 2003, 76, 489-499.

9 C. Smith, D. Sabatino and T. Praisner, Exp. Fluids, 2001, 30, 190-201.

10 Y. Han, K. Pacheco, C. W. Bastiaansen, D. J. Broer and R. P. Sijbesma, J. Am. Chem. Soc., 2010, 132, 2961-2967.

11 J. Stasiek, A. Stasiek, M. Jewartowski and M. Collins, Opt. Laser Technol., 2006, 38, 243-256.

12 A. Saha, Y. Tanaka, Y. Han, C. M. Bastiaansen, D. J. Broer and R. P. Sijbesma, Chem. Commun., 2012, 48, 4579-4581.

13 S. J. Woltman, G. D. Jay and G. P. Crawford, Nat. Mater., 2007, 6, 929-938.

14 S. Sivakumar, K. L. Wark, J. K. Gupta, N. L. Abbott and F. Caruso, Adv. Funct. Mater., 2009, 19, 2260-2265.

15 M. Bremer, P. Kirsch, M. Klasen-Memmer and K. Tarumi, Angew. Chem., Int. Ed., 2013, 52, 8880-8896.

16 J. Stöhr, M. Samant, A. Cossy-Favre, J. Diaz, Y. Momoi, S. Odahara and T. Nagata, Macromolecules, 1998, 31, 19421946.

17 J. J. Ge, C. Y. Li, G. Xue, I. K. Mann, D. Zhang, S.-Y. Wang, F. W. Harris, S. Z. Cheng, S.-C. Hong and X. Zhuang, J. Am. Chem. Soc., 2001, 123, 5768-5776.

18 K. Takatoh, M. Sakamoto, R. Hasegawa, M. Koden, N. Itoh and M. Hasegawa, in Alignment technology and applications of liquid crystal devices, CRC Press, 2005, pp. 7-8.

19 K. Ichimura, Chem. Rev., 2000, 100, 1847-1874.

20 J. Stöhr and M. Samant, J. Electron Spectrosc. Relat. Phenom., 1999, 98, 189-207.

21 M. Schadt, Annu. Rev. Mater. Sci., 1997, 27, 305-379.

22 A. Natansohn and P. Rochon, Chem. Rev., 2002, 102, 41394176.

23 M. Ree, Macromol. Res., 2006, 14, 1-33.

24 M. K. Ghosh and K. M. K. Polyimides, in Polyimides: Fundamentals and Applications, ed. M. Dekker, New York, 1996, pp. 806-807.

25 M. Feller, W. Chen and Y. Shen, Phys. Rev. A, 1991, 43, 67786792.

26 N. Van Aerle and A. Tol, Macromolecules, 1994, 27, 65206526.

27 K.-W. Lee, S.-H. Paek, A. Lien, C. Durning and H. Fukuro, Macromolecules, 1996, 29, 8894-8899.

28 K. Weiss, C. Wöll, E. Böhm, B. Fiebranz, G. Forstmann, B. Peng, V. Scheumann and D. Johannsmann, Macromolecules, 1998, 31, 1930-1936.

29 J. Stöhr, M. Samant, A. Cossy-Favre, J. Diaz, Y. Momoi, S. Odahara and T. Nagata, Macromolecules, 1998, 31, 19421946.

30 R. Meister and B. Jérôme, Macromolecules, 1999, 32, 480-486. 31 J. J. Ge, C. Y. Li, G. Xue, I. K. Mann, D. Zhang, S.-Y. Wang, F. W. Harris, S. Z. Cheng, S.-C. Hong and X. Zhuang, J. Am. Chem. Soc., 2001, 123, 5768-5776. 
32 D. Kim, M. Oh-e and Y. Shen, Macromolecules, 2001, 34, 9125-9129.

33 K. E. Vaughn, M. Sousa, D. Kang and C. Rosenblatt, Appl. Phys. Lett., 2007, 90, 194102.

34 S. Lee, S. Kim, Y. Park, M. Reea, Y. Rim, H. Yoon, H. Kim and Y. Kim, Mol. Cryst. Liq. Cryst., 2000, 349, 279-282.

35 Y. J. Lee, Y. W. Kim, J. D. Ha, J. M. Oh and M. H. Yi, Polym. Adv. Technol., 2007, 18, 226-234.

36 S. W. Lee, B. Chae, B. Lee, W. Choi, S. B. Kim, S. I. Kim, S.-M. Park, J. C. Jung, K. H. Lee and M. Ree, Chem. Mater., 2003, 15, 3105-3112.

37 S. B. Lee, G. J. Shin, J. H. Chi, W.-C. Zin, J. C. Jung, S. G. Hahm, M. Ree and T. Chang, Polymer, 2006, 47, 6606-6621.

38 H. Kang, J. S. Park, D. Kang and J. C. Lee, Polym. Adv. Technol., 2009, 20, 878-886.

39 H. Kang, T. H. Kim, D. Kang and J. C. Lee, Macromol. Chem. Phys., 2009, 210, 926-935.

40 S. Soumya and B. R. Nair, J. Agric. Sci. Technol., 2012, 8, 739750.

41 V. Fattori, M. S. Hohmann, A. C. Rossaneis, F. A. PinhoRibeiro and W. A. Verri, Molecules, 2016, 21, 844.

42 W. Glinski, M. Glinska-Ferenz and M. PierozynskaDubowska, Acta Derm.-Venereol., 1991, 71, 51-54.

43 A. Sánchez-Escalante, G. Torrescano, D. Djenane, J. A. Beltran and P. Roncales, J. Sci. Food Agric., 2003, 83, 187-194.

44 R. H. Cichewicz and P. A. Thorpe, J. Ethnopharmacol., 1996, 52, 61-70.

45 M. M. Cowan, Clin. Microbiol. Rev., 1999, 12, 564-582.

46 L. Dorantes, R. Colmenero, H. Hernandez, L. Mota, M. E. Jaramillo, E. Fernandez and C. Solano, Int. J. Food Microbiol., 2000, 57, 125-128.
47 K. Kim and K. Ryeom, Report of The National Institute of Health (Korea), 1979, vol. 16, pp. 241-251.

48 M. S. Tapia de Daza, S. M. Alzamora, J. W. Chanes and G. Gould, Crit. Rev. Food Sci. Nutr., 1996, 36, 629-659.

49 A. López-Malo, S. Alzamora and A. Argaiz, J. Food Sci., 1998, 63, 143-146.

50 S. D. Evans, E. Urankar, A. Ulman and N. Ferris, J. Am. Chem. Soc., 1991, 113, 4121-4131.

51 J. P. Lee, Y. J. Jang and M. M. Sung, Adv. Funct. Mater., 2003, 13, 873-876.

52 D. K. Owens and R. Wendt, J. Appl. Polym. Sci., 1969, 13, 1741-1747.

53 J. Swalen and G. Sprokel, in The Physics and Chemistry of Liquid Crystal Devices, Springer, 1980, pp. 39-46.

54 J. Fowles, R. Boatman, J. Bootman, C. Lewis, D. Morgott, E. Rushton, J. van Rooij and M. Banton, Crit. Rev. Toxicol., 2013, 43, 811-828.

55 U. Gedde, in Polymer physics, Chapman and Hall, London, 1995, ch. 5, pp. 78-79.

56 R. A. Hayes, J. Appl. Polym. Sci., 1961, 5, 318-321.

57 B. Wesslen, R. Lenz, W. MacKnight and F. Karasz, Macromolecules, 1971, 4, 24-26.

58 J. C. Lee, M. H. Litt and C. E. Rogers, J. Polym. Sci., Part B: Polym. Phys., 1998, 36, 75-83.

59 J.-B. Lee, H.-K. Lee, J.-C. Park and Y.-B. Kim, Mol. Cryst. Liq. Cryst., 2005, 439, 161-172.

60 S. W. Lee, S. J. Lee, S. G. Hahm, T. J. Lee, B. Lee, B. Chae, S. B. Kim, J. C. Jung, W. C. Zin and B. H. Sohn, Macromolecules, 2005, 38, 4331-4338.

61 B. A. MacDonald, K. Rollins, D. MacKerron, K. Rakos, R. Eveson, K. Hashimoto and B. Rustin, in Engineered films for display technologies, Wiley, 2nd edn, New York, 2005, pp. 11-33. 